\title{
Workplace Violence Against Doctors in Khartoum State, Sudan, 2020
}

\section{Muna Mohamed Elamin1, Salih Boushra Hamza 2,3, Khabab Abbasher ${ }^{4}$, Khalid Elsir Idris ${ }^{3,5}$, Yassin Abdelrahim Abdallah ${ }^{2,3}$, Khadija Ala Abdalmaqsud Muhmmed ${ }^{3,6}$, Tibyan Hassan Mustafa Alkabashi ${ }^{7}$, Radi Tofaha Alhusseini ${ }^{8}$, Sidieg Elias Sidieg Mohammed ${ }^{3,9}$, and Ahmed Alsayed Mohammed Mustafa 3,10}

${ }^{1}$ Community Department, Faculty of Medicine, Omdurman Islamic University, Khartoum, Sudan

${ }^{2}$ Department of Internal Medicine, Faculty of Medicine and Health Sciences, Omdurman Islamic University, Khartoum, Sudan

${ }^{3}$ Pso_Research Unit

${ }^{4}$ Faculty of Medicine, University of Khartoum, Khartoum, Sudan

${ }^{5}$ Department of Microbiology, Faculty of Medicine and Health Sciences, Omdurman Islamic University, Khartoum, Sudan

Corresponding Author: Salih Boushra Hamza; Department of Internal Medicine, Faculty of Medicine and Health Sciences,

Omdurman Islamic University, Omdurman, Khartoum,

Sudan.

Phone Number:

+249999253222

email:

salihboushra@gmail.com

Received 27 March 2021

Accepted 9 May 2021

Published 30 June 2021

Production and Hosting by Knowledge E

(c) Muna Mohamed Elamin et al. This article is distributed under the terms of the

Creative Commons

Attribution License, which

permits unrestricted use and redistribution provided that the original author and source are credited.

Editor-in-Chief:

Prof. Mohammad A. M. Ibnouf
${ }^{6}$ Department of Anatomy, Faculty of Medicine and Health Sciences, Omdurman Islamic University, Khartoum, Sudan

${ }^{7}$ Department of Pathology, Faculty of Medicine and Health Sciences, Omdurman Islamic University, Khartoum, Sudan

${ }^{8}$ Department of Anatomy, Alzaiem Alazhari University, Khartoum, Sudan

${ }^{9}$ Faculty of Medicine and Health Sciences, Omdurman Islamic University, Khartoum, Sudan

${ }^{10}$ Faculty of Medicine and Health Sciences, Omdurman Islamic University, Khartoum, Sudan

ORCID:

Salih Boushra Hamza: https://orcid.org/0000-0002-0231-2206

Khalid Elsir Idris: https://orcid.org/0000-0002-7780-9436

Yassin Abdelrahim Abdallah: https://orcid.org/0000-0003-1981-8665

Yassin Abdelrahim Abdallah: https://orcid.org/0000-0003-0369-5138

Tibyan Hassan Mustafa Alkabashi: https://orcid.org/0000-0002-0897-1528

Sidieg Elias Sidieg Mohammed: https://orcid.org/0000-0002-1819-489X

\section{Abstract}

Background: Workplace violence against healthcare workers and especially doctors are now clearly taken as a rapidly rising health problem in Sudan with great political and legal concerns. The current study was aimed at exploring the prevalence of verbal and physical workplace violence, the major factors associated with it, and its consequences reported by medical staff in Khartoum, Sudan government hospitals in 2020.

Methods: This cross-sectional study utilized self-administered questionnaires to collect data on aspects of workplace violence against doctors working in the government hospitals of Khartoum, Sudan. A nine-item self-reported workplace violence scale was used. An online survey of self-reported work-related violence exposure during the preceding 12 months was sent to conveniently selected doctors. In total, 387 doctors completed the questionnaire in 2020. Data were analyzed using the SPSS version 26.
Radi Tofaha Alhusseini: https://orcid.org/0000-0002-7778-5331

\section{G OPEN ACCESS}


Results: One hundred and ninety five (50\%) respondents reported they were victims of violence in the previous 12 months; $92 \%$ of them experienced nonphysical violence; while female doctors were more likely to experience this type of violence (67\%), younger respondents $<30$ years of age were more likely to encounter violent episodes. Results show an association between exposure to physical violence and working at an emergency department. The assailants were mostly males in the age group of 19-35 years (70.2\%), most of them were under no influence (60.8\%).

Conclusion: Approximately one in every two doctors had experienced some degree of violence, either physical or nonphysical or both, and it was negatively reflected on their psychological status as well as their work performance.

Keywords: violence, workplace, doctors, physical, nonphysical

\section{Introduction}

The word "violence" originates from the Latin word violentia, which means a behavior involving physical force intended to hurt, damage someone [1]. Workplace violence (WPV) is an act of aggression, physical assault, or threatening behavior that occurs in a work setting and causes physical or emotional harm to an employee [2]

WPV is a well-recognized occupational hazard for victims with physical, emotional, and behavioral effects [3]. It can be defined as violence or threat of violence against workers. It can occur at or outside the workplace and can range from threats, verbal abuse to physical assault and homicide [4]. The World Health Organization (WHO) defines WPV as incidents where staff are abused, threatened, or assaulted in circumstances related to their work including commuting to and from work involved and explicit or implicit challenge to their safety, well-being, or health. According to the WHO, WPV can be classified as physical, psychological (emotional), sexual, and racial [5].

\subsection{Violence against doctors}

The medical profession, once thought to be dignified and treasured, is losing its reputation. It is in danger particularly from the patients and their relatives. Gone are the days when doctors used to put all of their efforts to breathe life into patients in the near-death state, sadly frequent attacks on doctors are changing the scenario [6]. Violence toward doctors is regarded as a major public health challenge. Healthcare staffs are vulnerable 
to WPV [7] because they work at the core of the healthcare system and have a direct interaction with patients and their families [8].

\subsection{Factors that increase WPV}

The rising cases of violence against doctors have made society think about the causes and prevention of such incidences. In many instances, after a patient dies, the patient's relatives start blaming doctors for negligence over the treatment [6]. Poor image of doctors and the role of the media are other important factors [6]. The increasing cost of healthcare combined with low faith in the jurisdictive process is sufficient to cause debt and frustration in many families. Although many medical institutions are emphasizing the cognitive and psychomotor domain of the healthcare students (e.g., pharmacy students), they lack in developing the effective domain [9]. This is resulting in a gap between doctors and patients. Doctors are taught clinical behavior but not empathy. Less time is given to communicate the prognosis of the disease and the outcome of treatment, resulting in dissatisfaction with healthcare services among patients. Government hospitals top the list of WPV due to lack of resources and time. Sometimes patients have to wait for a long time outside the doctor's chamber as the crowd makes them panic. Oftentimes patients do not get emergency care within the golden hour. These are some of the precipitating factors.

Occupational Safety and Health Administration (OSHA), USA, describes workers who provide services, work in remote or high-crime areas, and those who work shift hours and/or have a great deal of contact with the public are at risk. This group includes healthcare workers such as physicians, nurses, other providers (both community- and hospital-based), social workers, and psychiatric evaluators [10].

\subsection{Impact of WPV}

WPV against healthcare workers has long-lasting, deleterious effects on the victim's health resulting in stress, emotional shock, reduced efficiency and productivity due to physical and psychological trauma, and sometimes changing or even leaving the profession [11].

According to Gilbert Burnham and colleagues' study, the number of medical specialists in Baghdad declined by 22\% between 2004 and 2007 due in part to violent deaths (1.65\%), threats (3\%), and kidnappings (0.67\%) [12]. Iraqi doctors are getting assaulted, violated, and humiliated, and as a result, more physicians are leaving the country. 
More than 2,000 doctors have been killed since 2003 [13]. A cross-sectional study was conducted in Ghana to determine the effect of WPV on nurses' emigration intentions between 2013 and 2014. Both purposive and random sampling techniques were used to select 12 public hospitals and 592 professional nurses. The results showed that $48.9 \%$ of the participants had emigration intentions. Junior nurses were 2.8 times more likely to have emigration intentions compared to senior nurses, and those who experienced violence were also more likely than their counterparts who were not involved in such incidents (physically abused 2.1 times; verbally abused 1.8 times, and sexually harassed 2.4 times) to have intention to emigrate $[14,15]$.

\subsection{WPV against healthcare workers in Sudan}

WPV against healthcare workers and especially doctors in Sudan is an issue that has yet not received considerable critical attention from the local healthcare system authorities even with the increasing rate of violence against healthcare workers in Khartoum state, Sudan. Violence in workplace and in healthcare sector has a significant impact on the efficacy of health systems, especially in developing countries [16, 17], which ultimately leads to negative patient outcomes.

Several studies have shown that WPV affects the physical and mental health of healthcare workers [18-22].

This study aims to assess the rate of attacks in the last 12 months, measure violence rates by sociodemographic factors, and possible risk factors for WPV against physicians working in governmental hospitals in Khartoum State, Sudan. The study also examines the consequences of violence, related psychosocial results and their effect on the doctors and their performance, professionals' incident reporting patterns, and existing violence prevention and safety measures applied by hospital authorities from healthcare workers' perspectives.

\section{Materials and Methods}

\subsection{Participants}

This cross-sectional study targeted doctors working in the government hospitals of Khartoum state, Sudan and included a total of 387 doctors. Data were collected using a convenience sampling technique. 
The sample size was calculated using the sample size of the unknown population (Cochran's formula): $\mathrm{n}_{0}=\frac{z^{2} p(1-p)}{e^{2}}$,

Where, $z=z$-value (1.96 for $95 \%$ confidence interval);

$p=$ probability of WPV ( $p$ is unknown, so it was considered as 0.5 );

$e=$ error margin; and

$\mathrm{n}_{0}=(1.96)^{2} \times 0.5(1-0.5) \div(0.05)^{2}=384$.

\subsection{Measures}

A reliable and validated well-structured questionnaire was obtained from a previous study conducted by Mohamad Kitaneh and Motasem Hamdan (with their due permission) [23]. The study instrument was prepared on the basis of the questionnaires used in the two previous studies $[24,25]$. Reliability test revealed a 0.7 Cronbach's alpha (considered reliable). All Pearson's correlations were above critical value (considered valid). The instrument was modified to fit the objectives of the study and the Palestinian hospital context and was translated into Arabic. It was reviewed by five experts (nurses and physicians) for its validity. Experts assessed the clarity, relevance, comprehensiveness, and sensitivity of the tool to the culture. In essence, the expert comments were about the definitions of violence, in specific sexual violence, and the clarity of some questions. The modified questionnaire was then pilot tested. The questionnaire consisted of four sections: the first section included sociodemographic data, the second one was about the history of exposure to physical violence, the third section was about nonphysical violence (threats, verbal violence, and sexual violence), and the last section contained questions on the characteristics of perpetrators, magnitude, and consequences of violence, incident reporting, availability of policies/procedures, training programs, and safety measures in the workplace.

\subsection{Procedure}

As our study was conducted in unusual circumstances, where most social activities were restricted to a maximum reduction in person-to-person contacts as part of COVID-19 pandemic control measures, data were collected using an Internet-mediated questionnaire. The questionnaire was restrictedly distributed throughout the doctor's group in social media. 


\subsection{Data analysis}

Data were analyzed using the Statistical Package for Social Science (SPSS) version 26 and are presented in tables and graphs, after being primarily analyzed by Google form. Descriptive analysis was used to describe the demographic data, incidence of violence, and the magnitude and consequences of violent events. Pearson's Chi-square analysis was used to test the differences in exposure to violence (physical and nonphysical violence) according to respondents' characteristics. Odds ratios and 95\% confidence intervals were used to assess potential association between exposure to violence in general (yes/no) and respondents' characteristics including gender, age, years of experience, educational level, and hospital department. An adjustment was then made for the same pre-mentioned covariates using a logistic regression model; the dependent variable was exposure to violence (yes, no). A $p$-value $<0.05$ was considered statistically significant.

\section{Results}

\subsection{Demographic characteristics}

Of the total participants, 297 (76.7\%) were aged $\leq 30$ years and most of them were female 236 (61\%). Moreover, majority of them were medical officers (128 [33.1\%]) holding a bachelor's degree in medicine (318 [82.2\%])

\subsection{Incidence of violence against doctors in government hospitals}

\subsubsection{Doctor's exposure to violence}

About 195 (50\%) participants experienced one type of violence, either physical or nonphysical (verbal or sexual abuse, or threat), within the preceding year; $92 \%$ of them (49\% of all participants) experienced nonphysical and 8 participants ( $1 \%$ of all participants) experienced physical violence.

\subsubsection{Nonphysical violence}

Most participants (40\%) experienced verbal abuse and threat at the same time, followed by only verbal violence by $36 \%$ and exposure to both physical and nonphysical violence during the past 12 months (Figure 1) by $15 \%$. 


\subsubsection{Association between exposure to violence and respondent's characteristics}

Table 3 shows the descriptive association between respondents' characteristics and exposure to physical and nonphysical violence in the past 12 months. The results indicated that there is an association between gender and exposure to nonphysical violence $(p$-value $=0.004)$. However, female doctors were more likely to be exposed to nonphysical violence than their male counterparts. Similarly, those aged $<30$ years reported experiencing a higher incidence of violence (64.4\%) than those aged $>30$ years $(p$-value $=0.024)$. Moreover, medical officers reported the highest incidence $(65 \%)$, followed by house officers $(62.7 \%)$ and registrars $(61 \%)(p$-value $=0.02)$. Those who worked in shifts had a significantly increased risk $(63 \%)(p$-value $=0.04)$. There were no associations between work experience or department and exposure to nonphysical violence, and between exposure to physical violence and gender, age, profession, education, years of experience, or work shift. However, an association was found between exposure to physical violence and working at the emergency department $(p$-value $=0.0001)($ Table 1$)$.

Multivariate logistic regression analysis identified significant predictors for violence exposure. While males were 1.5 times more likely to be victims of violence compared to females $(p$-value $=0.044)$, healthcare workers in the emergency department experienced violence 2.5 times more compared to the other departments ( $p$-value $=0.001$ ). Adjusted linear regression revealed no significant difference when multivariate analysis for age and sex, and age and rank was conducted and no interaction was found.

Holding a bachelor's degree was associated with a half-time decrease in violence exposure compared to holding a higher degree $(p$-value $=0.009)$. Although participants aged $\leq 30$ years were twice more likely to experience violence than those aged $>30$ years, this association became insignificant after adjustment (Table 2).

\subsubsection{Characteristics of perpetrators and violent events}

Most perpetrators (70.2\%) were in the age group of $19-35$ years. The attacks on our participants mostly occurred (71.6\%) during the past 12 months and were usually carried out by males. The worst violent attacks mostly occurred during the working days (69.9\%) with few incidences occurring on weekends (16.2\%) while the rest were unsure (14.8\%). Most physical assaults (54\%) occurred in the evening, and most perpetrators were under no influence $(60.8 \%)$ when they attempted to attack our participants. Few of them were 
TABLE 1: Association between exposure to violence and respondents' characteristics.

\begin{tabular}{|c|c|c|c|c|c|c|c|c|}
\hline & \multicolumn{4}{|c|}{ Physical violence } & \multicolumn{4}{|c|}{ Nonphysical violence } \\
\hline & $N$ & $\%$ & $x^{2}$ & $P$-value & $N$ & $\%$ & $x^{2}$ & $P$-value \\
\hline \multicolumn{9}{|l|}{ Gender } \\
\hline Male & 34 & 22.5 & $1.846^{a}$ & 0.174 & 79 & 52.3 & $8.305^{a}$ & 0.004 \\
\hline Female & 40 & 18.6 & & & 158 & 67 & & \\
\hline \multicolumn{9}{|l|}{ Age (yr) } \\
\hline$<30$ & 60 & 20.2 & $0.964^{a}$ & 0.326 & 191 & 64.3 & $5.069^{a}$ & 0.024 \\
\hline$>30$ & 14 & 15.5 & & & 46 & 51 & & \\
\hline \multicolumn{9}{|l|}{ Profession } \\
\hline House officer & 16 & 14.5 & $6.363^{a}$ & 0.174 & 69 & 62.7 & $11.724^{a}$ & 0.020 \\
\hline Medical officer & 34 & 25 & & & 83 & 65 & & \\
\hline Registrar & 24 & 19 & & & 77 & 61 & & \\
\hline Specialist & 2 & 11.7 & & & 8 & 47 & & \\
\hline Consultant & 0 & 0 & & & 0 & 0 & & \\
\hline \multicolumn{9}{|l|}{ Education } \\
\hline Bachelor's degree & 3 & 7.6 & $3.663^{a}$ & 0.056 & 18 & 46 & $4.159^{a}$ & 0.041 \\
\hline >Bachelor's degree & 71 & 20.4 & & & 219 & 63 & & \\
\hline \multicolumn{9}{|l|}{ Experience (yr) } \\
\hline$\leq 10$ & 70 & 18.67 & 1. $617^{a}$ & 0.203 & 191 & 64.3 & $5.069^{a}$ & 0.695 \\
\hline$\geq 10$ & 4 & 33 & & & 46 & 51 & & \\
\hline \multicolumn{9}{|l|}{ Work in shift } \\
\hline Yes & 71 & 20.4 & $3.663^{a}$ & 0.056 & 219 & 63 & $4.159^{a}$ & 0.041 \\
\hline No & 3 & 7.7 & & & 18 & 46 & & \\
\hline \multicolumn{9}{|l|}{ Department } \\
\hline Emergency & 29 & 36.7 & $19.854^{a}$ & 0.000 & 55 & 69.6 & $2.937^{a}$ & 0.087 \\
\hline Others & 45 & 14.6 & & & 182 & 59 & & \\
\hline
\end{tabular}

under the influence of drugs taken as a form of addiction. Regarding the tool of attack used, most perpetrators used their hands and feet $(77 \%)$ to attack our participants. Few male perpetrators (5.4\%) used knives and few female perpetrators (2.7\%) used the surrounding objects as a tool of attack. The results related to the magnitude of the violent incidents showed that the majority of the participants reported exposure to single physical violent (71.7\%) and single nonphysical violent (25.5\%) event; repeated events were $28.3 \%$ and $74.4 \%$, respectively. Physical violence occurred mostly in the examination room (36.1\%) (Table 3). 
TABLE 2: Unadjusted and multivariate-adjusted odds ratios for exposure to violence among respondents.

\begin{tabular}{|c|c|c|c|c|c|c|}
\hline & \multicolumn{2}{|c|}{ Unadjusted } & \multirow[t]{2}{*}{$P$-value } & \multicolumn{2}{|c|}{ Adjusted* } & \multirow[t]{2}{*}{$P$-value } \\
\hline & OR & $95 \% \mathrm{Cl}$ & & OR & $95 \% \mathrm{Cl}$ & \\
\hline \multicolumn{7}{|l|}{ Gender } \\
\hline Male & 1.513 & $0.988-2.318$ & 0.057 & 1.589 & $1.012-2.495$ & 0.044 \\
\hline Female & 1.0 & Reference & & 1.0 & Reference & \\
\hline \multicolumn{7}{|l|}{ Age (yr) } \\
\hline$\leq 30$ & 1.835 & $1.134-2.972$ & 0.014 & 1.660 & $0.984-2.801$ & 0.057 \\
\hline$>30$ & 1.0 & Reference & & 1.0 & Reference & \\
\hline \multicolumn{7}{|l|}{ Department } \\
\hline Emergency & 2.686 & $1.464-4.930$ & 0.001 & 2.914 & $1.561-5.441$ & 0.001 \\
\hline Others & 1.0 & Reference & & 1.0 & Reference & \\
\hline \multicolumn{7}{|l|}{ Education } \\
\hline Bachelor's degree & 0.412 & $0.211-0.408$ & 0.009 & 0.397 & $0.193-0.819$ & 0.012 \\
\hline >Bachelor's degree & 1.0 & Reference & & 1.0 & Reference & \\
\hline \multicolumn{7}{|l|}{ Experience (yr) } \\
\hline$<10$ & 0.942 & $0.278-3.188$ & 0.924 & 0.404 & $0.103-1.591$ & 0.195 \\
\hline$\geq 10$ & 1.0 & Reference & & 1.0 & Reference & \\
\hline
\end{tabular}

${ }^{*}$ Adjusted for independent variables: Gender, experience, education, age, and department.

OR: Odds ratios, $\mathrm{Cl}$ : Confidence interval; Reference: Reference category in the logistic regression model.

\subsubsection{Consequences of violent events}

While the most frequent consequences of physical and nonphysical violence was anger (22.7\% and $23.4 \%$, respectively), the rarest was difficulty in sleeping (6\% and $4 \%$ ) but only $0.3 \%$ and $3.6 \%$ had no consequence, respectively. Most participants did not seek treatment for both physical and nonphysical violence $(64.3 \%$ and $78.7 \%$, respectively). Most of them treated themselves following a physical and nonphysical violence (32.8\% and 23.7\%, respectively). Most participants' problems did not persist following the physical or nonphysical violence (63.5\% and $69 \%$, respectively). Likewise, most participants had no change in work after a physical or nonphysical violence (53\% and $71 \%$, respectively). The most frequent change in work was absence from work due to physical violence (19.4\%) and work restrictions regarding nonphysical violence (16.6\%)

While $79.1 \%$ of the respondents did not report the incident, only $20.6 \%$ of them reported and most of them (79.9\%) took no legal action on their cases. Of those who did not report the event, $34.5 \%$ indicated they did so because it was useless, from their experience no action would be taken; $13.4 \%$ did not know to whom they should report; $8.5 \%$ indicated that reporting was not important; $5 \%$ were afraid of negative consequences or fear of feeling guilty or ashamed; and $1.4 \%$ cited other causes. The majority of respondents (79.3\%) indicated the absence of standard procedures 
TABLE 3: Characteristics of perpetrators.

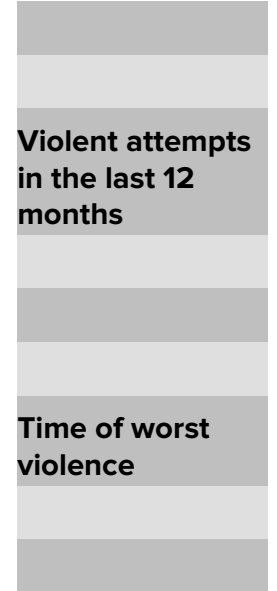

Perpetrator's age group (yr)

Perpetrator's
status

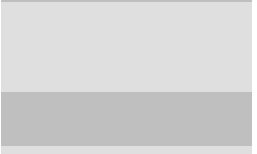

Time of violence

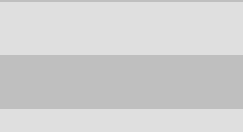

Tool of violence

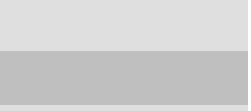

Drugs such as opiates.

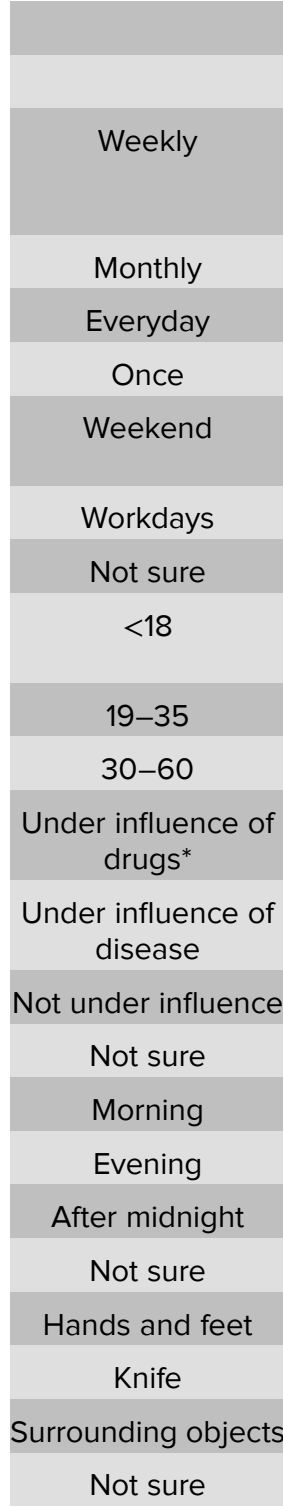

\begin{tabular}{|c|}
\hline Male (\%) \\
\hline 60 (81.1) \\
\hline $2(2.7)$ \\
\hline 17 (22.9) \\
\hline $1(1.3)$ \\
\hline $40(54)$ \\
\hline $10(13.5)$ \\
\hline $41(55.4)$ \\
\hline 9 (12.1) \\
\hline $0(0.0)$ \\
\hline $45(60.8)$ \\
\hline $15(20.2)$ \\
\hline $3(4)$ \\
\hline $5(6.7)$ \\
\hline $33(44.5)$ \\
\hline $19(25.6)$ \\
\hline $18(24.3)$ \\
\hline $28(37.8)$ \\
\hline 13 (17.5) \\
\hline $1(1.3)$ \\
\hline $46(62.1)$ \\
\hline $4(5.4)$ \\
\hline $0(0.0)$ \\
\hline $10(13.5)$ \\
\hline
\end{tabular}

$10(13.5)$

\begin{tabular}{|c|}
\hline Female (\%) \\
\hline $14(18.9)$ \\
\hline $0(0.0)$ \\
\hline $1(1.3)$ \\
\hline $0(0.0)$ \\
\hline $13(17.5)$ \\
\hline $2(2.7)$ \\
\hline $10(13.5)$ \\
\hline $2(2.7)$ \\
\hline $1(1.3)$ \\
\hline $7(9.4)$ \\
\hline $6(8.1)$ \\
\hline $0(0.0)$ \\
\hline $0(0.0)$ \\
\hline $12(16.2)$ \\
\hline $2(2.7)$ \\
\hline $4(5.4)$ \\
\hline $2(2.7)$ \\
\hline $7(9.4)$ \\
\hline $1(1.3)$ \\
\hline $1(14.8)$ \\
\hline
\end{tabular}

\begin{tabular}{|c|}
\hline Total \% \\
\hline 2.7 \\
\hline 24.2 \\
\hline 1.3 \\
\hline 71.5 \\
\hline 16.2 \\
\hline 68.9 \\
\hline 14.8 \\
\hline 1.3 \\
\hline 70.2 \\
\hline 28.3 \\
\hline 4 \\
\hline 6.7 \\
\hline 60.7 \\
\hline 28.3 \\
\hline 29.7 \\
\hline 40.5 \\
\hline 26.9 \\
\hline 2.7 \\
\hline 76.9 \\
\hline 5.4 \\
\hline 2.7 \\
\hline 14.8 \\
\hline
\end{tabular}

for reporting violence or any encouragement to report events. Most of them also indicated that the hospitals had no specific policy/procedure or training programs on WPV (85-95\%). Some participants had received training on some of the following issues: safety measures (10.6\%), dealing with violence (4.7\%), communication (34.1\%), and stress management (8.3\%). A very low percentage indicated the availability of violencepreventing policies/procedures related to verbal abuse (5.2\%), health and safety (10.6\%), physical violence (10.9\%), threats (5.9\%), and sexual harassment (5.7\%). The respondents were also asked about the measures that exist in the work environment to deal with violence. The most frequently rated safety measures were as follows: security personnel 
TABLE 4: Characteristics and consequences of violent assault.

\begin{tabular}{|c|c|c|c|c|}
\hline & \multicolumn{2}{|c|}{ Physical } & \multicolumn{2}{|c|}{ Nonphysical } \\
\hline & $N$ & $\%$ & $N$ & $\%$ \\
\hline \multicolumn{5}{|l|}{ Symptoms/feeling } \\
\hline Anger & 48 & 22.7 & 161 & 23.4 \\
\hline Depression & 27 & 12.7 & 81 & 11.8 \\
\hline Fear/stress & 27 & 12.7 & 102 & 14.8 \\
\hline Headache/fatigue & 18 & 8.3 & 60 & 8.7 \\
\hline Frustration & 42 & 19.9 & 113 & 16.4 \\
\hline Confusion at work & 36 & 17 & 116 & 16.9 \\
\hline $\begin{array}{l}\text { Difficulty in } \\
\text { sleeping }\end{array}$ & 3 & 6 & 28 & 4 \\
\hline Nothing & 1 & 0.3 & 25 & 3.6 \\
\hline \multicolumn{5}{|l|}{ Treatment } \\
\hline No treatment & 47 & 64.3 & 294 & 78.7 \\
\hline Physician & 1 & 1.3 & 0 & 0 \\
\hline I treated myself & 24 & 32.8 & 92 & 23.7 \\
\hline Psychiatrist & 1 & 1.3 & 3 & 9 \\
\hline \multicolumn{5}{|c|}{ Persistent problem as a result } \\
\hline Yes & 27 & 36. 4 & 123 & 31 \\
\hline No & 47 & 63.6 & 274 & 69 \\
\hline \multicolumn{5}{|c|}{ Work change as a result } \\
\hline No changes & 41 & 53 & 275 & 71.1 \\
\hline $\begin{array}{l}\text { Transfer to } \\
\text { another location }\end{array}$ & 6 & 7.7 & 23 & 6.6 \\
\hline Restrictions & 12 & 15.5 & 62 & 16.6 \\
\hline Absence & 15 & 19.4 & 27 & 8.1 \\
\hline Other & 3 & 3.8 & 0 & 0 \\
\hline
\end{tabular}

(79.6\%), security alarms (2.6\%), video monitoring systems (16.8\%), cell phones (2.8\%), and metal detectors (1.6\%) (Table 4).

\section{Discussion}

Most respondents in the current study were females (61\%) which is similar to the Kitaneh and Hamdan's study [23], however, in the current study [23], the most common age group of respondents was $\leq 30$ years while their respondent's ages ranged from 20 to 29 years. Most respondents in this study were medical officers (33.1\%) followed by registrars (32.6\%) and house officers (28.4), and most of them (20.4\%) worked in the emergency department which is similar to the study of Kitaneh and Hamdan [23]. 
Our study showed that $65 \%$ of the participants were exposed to WPV during the past 12 months. Although there were some differences in the targeted professional groups and in the methodology used, the study outcomes are comparable with previous regional and international studies. In general, the exposure to violence of healthcare workers working in the government hospitals of Khartoum (65\%) was greater than in a study conducted in Egypt (60\%) [26], however, both studies had a similar rate of physical violence against physicians (15.1\% in Egypt and 16\% in Sudan). A study from Pakistan revealed that violence against doctors was found to be almost similar to our findings (63.8 \%) [27], another similar study from Nigeria showed a low incidence of violence against physicians (57.4\%) [28], while a Palestinian survey exhibited an $80 \%$ incidence of violence which is greater than our finding [23]. The fact that the majority of respondents were exposed to some type of violence is in itself a matter of concern. A conceivable explanation for these results could be related to the unsatisfactory working conditions including frequent deficiencies of medications and supplies, overcrowded hospitals, and delays in getting care as well as neglected patient needs or expectations, long working hours, and poor working environment for government doctors, which makes them vulnerable to committing mistakes and more prone to violence. It can be accepted that the fragile financial conditions of the nation might be another important causative factor. Difficult living conditions, disappointment, and stress within the Sudanese lifestyle increase the forceful conduct against doctors; in any case, these variables were not inspected in this study.

Surprisingly, both genders were equally exposed to violence and no statistically significant difference was seen; however, when adjusted, it showed an $\mathrm{OR}=1.5 ; \mathrm{Cl}$ $=95$ among males in comparison to females ( $p$-value $=0.04)$. This contradicts the literature that males and females are equally likely to encounter WPV [25, 29, 30]. The emergency ward is a characteristically high-pressure environment and experiences a high load of patients. Due to several factors involving the patient's condition at arrival and the state of severe anger and anxiety that patients and co-patients feel when they arrive at emergency departments, this makes these areas the venue of the highest rates of patient or visitor violence [17, 31-34]. In our study, we found that healthcare workers in the emergency department experienced violence 2.5 times more compared to other departments ( $p$-value $=0.001$ ) before and after adjustment with $\mathrm{OR}=2.68$ and 2.91, respectively. One interesting finding was that holding a bachelor's degree was a factor associated with violence exposure $(p$-value $=0.009)$ and it was strengthened after adjustment ( $p$-value $=0.01 ; \mathrm{OR}=0.41$ and 0.39 , respectively; $\mathrm{Cl}=95 \%$ ). 
Inconsistent with other studies from Arab countries in the region $[23,28,35,36]$, our study showed that males more than females were exposed to violence (81.1\%), however, it aligned with other studies [23, 28, 35-37] that revealed that respondents with lower educational level were associated with higher exposure rate to violence ( $p$-value $=0.01)$. Many studies have recognized that the emergency department is a particularly violent environment $[38,39]$, in our study also, healthcare workers in the emergency department experienced violence 2.5 times more compared to those in other departments ( $p$-value $=0.001)$. These departments are usually attended by aggressive and stressed patients/visitors and those patients who are impaired by drugs and are more likely to commit violence against health workers [40-42].

The attacks on our patients mostly occurred in the past 12 months and were generally carried out by males; the results of our study are in line with the previous study which noticed that the majority of the incidents were single events [23]. The majority of perpetrators were in the age group of 19-35 years, which can be explained by the strength of youth. The attack mostly occurred during working days (from Sunday to Thursday) with few incidences occurring on the weekends. The time of the attack was mostly in the evening. Similar results have been reported in previous studies in the region $[23,35,36,40,41]$. Moreover, most perpetrators were under no influence of drugs or alcohol when they attempted to attack our participants, this result is similar to a previous study [23]. In most cases, the perpetrators used their hands and feet to attack our participants. Few male perpetrators used knives and few female perpetrators used the surrounding objects as a tool of attack; hence, men are more likely and physically capable of enacting physical violence than women who are more likely to enact verbal violence $[29,38,40,41]$.

As mentioned in many previous studies, the patients and their relatives are reported as the core of violence $[5,16,18,20,26,42,43]$. Most participants who were exposed to physical or nonphysical assault did not receive any kind of treatment $(63.5 \%$ and $75.4 \%$, respectively). This should be highlighted, especially as evidence shows that WPV usually results in short- and long-term effects on the victims' physical, psychological state, and professional performance $[43,44]$. It is not a surprise that most of our respondents indicated psychological and emotional feelings such as anger, fear, depression, stress, and frustration. In previous studies, it appeared that individuals who experience nonphysical violence endured feelings/symptoms over time, with a possible risk for adverse mental health outcomes such as acute stress disorder or posttraumatic stress syndrome [32, 33]. Anger was slightly higher among those who experienced nonphysical violence, mostly due to the large number of participants who experienced 
this type of violence compared to physical violence. We can see that about 152 (77.9\%) of those who experienced physical or nonphysical violence reported subsequent changes in their work status, including absence, subsequent transfer to another location, and restrictions in work. However, this seems to be much higher than the available data $[18,26]$.

\section{Conclusion}

Violence remains a special concern to doctors working in healthcare facilities in Sudan. According to our data, approximately one in every two doctors has experienced some degree of violence, either physical or nonphysical. Exposure to violence is negatively reflected in the psychological status and the level of their work performance. The prevalence of WPV on doctors in Sudan identified in this study was high, and in many events, the associated factors were found. Underreporting plays a major role in augmenting the violent incidences, there is a serious lack of reporting procedures and even encouragement to report these events. There is also a lack of violence prevention policies in healthcare facilities. We are holding useful data that can be used by researchers to address and further study this issue.

\section{Recommendations}

Since the majority of violent events were nonphysical, strategies to decrease and control this type of violence are recommended. Because most of the affected persons were working in the emergency department and most incidents occurred in the evening, strategy to control violence in that particular setting and time is mandatory. The hospital reporting system for violence is highly needed to be reviewed and improved, and doctors should be encouraged to report. Training workshops to deal with and avoid violence should be conducted. Further studies are recommended after a while to assess the effectiveness of Sudan's law on the protection of doctors, medical staff, and health establishments, May 29, 2020. Future studies should be done to explore the violence determinants and how to avoid them.

\section{Limitations}

1. An online questionnaire was used to collect data in this study. Although it is a flexible and cost-effective way of data collection, it has low acceptance as a 
data collection tool, and due to a lack of interactivity between the respondent and researcher, it affects the researcher's ability to authenticate an individual's responses.

2. Difficulty reaching certain types of participants, such as those who do not have Internet access, is another limitation.

3. In some responses, exposure to violence may be under/over-reported by the participating doctors due to the fluctuation of their memory because of the time gap between the violence incidence and the questionnaire-filling date.

\section{Acknowledgements}

None.

\section{Ethical Considerations}

Permission to conduct the study and ethical approval was obtained from the Ethical Committee of the Faculty of Medicine and Health Sciences, Omdurman Islamic University, Federal Ministry of Health. A written consent was obtained from all participants after explaining the aim of the study and assuring the confidentiality of their data. All methods were performed following the relevant guidelines and regulations.

\section{Competing Interests}

The authors declare that they have no competing interests.

\section{Availability of Data and Materials}

The materials and datasets used and/or analyzed during this study are available from the corresponding author upon reasonable request.

\section{Funding}

This research did not receive any specific grants from funding agencies in the public, commercial, or not-for-profit sectors. 


\section{References}

[1] Violence. (n.d.). In Oxford Dictionary on Lexico.com. Retrieved from: https://www. lexico.com/definition/violence

[2] USLegal, Inc. (n.d.). In Workplace Violence Law and Legal Definition. Retrieved from: https://definitions.uslegal.com/w/workplace-violence/

[3] FitzGerald, D. and Reid, A. (2012). Frequency and consequences of violence in community pharmacies in Ireland. Occupational Medicine, vol. 62, no. 8, pp. 632663.

[4] Papa, A. and Venella, J. (2013). Workplace violence in healthcare: strategies for advocacy. Online Journal of Issues in Nursing, vol. 18, no. 1, manuscript 5.

[5] WHO. (2002). Framework Guidelines for Addressing Workplace Violence in the Health Sector. Geneva, Switzerland: International labour Office (ILO), International Council for Nurses (ICN), World Health Organization (WHO), Public services international (PSI). Retrieved from: who.int/violence_injury_prevention/violence/activities/work-place/en/

[6] Dahal, K. (2008). Angry relatives attack doctors and hospitals in Nepal. BMJ, vol. 337, p. a1946.

[7] Li, Z., Yan, C. M., Shi, L., et al. (2017). Workplace violence against medical staff of Chinese children's hospitals: a cross-sectional study. PLOS ONE, vol. 12, no. 6, p. e0179373.

[8] Chen, S., Lin, S., Ruan, Q., et al. (2016). Workplace violence and its effect on burnout and turnover attempt among Chinese medical staff. Archives of Environmental \& Occupational Health, vol. 71, no. 6, p. 3307.

[9] Muzyk, A., Lentz, K., Green, C., et al. (2017). Emphasizing bloom's affective domain to reduce pharmacy students' stigmatizing attitudes. American Journal of Pharmaceutical Education, vol. 81, no. 2, p. 35.

[10] US Department of Labor. (n.d.). OSHA Fact Sheet. Retrieved from: www.osha.gov/ OshDoc/data_General_Facts/factsheet-workplace-violence.pdf

[11] di Martino, V. (2003). Workplace Violence in the Health Sector: Relationship Between Work Stress and Workplace Violence in the Health Sector. Geneva: ILO/ICN/WHO/PSI. Retrieved from: https://www.who.int/violence_injury_prevention/ violence/interpersonal/WVstresspaper.pdf

[12] Burnham, G. M., Lafta, R., and Doocy, S. (2009). Doctors leaving 12 tertiary hospitals in Iraq, 2004-2007. Social Science \& Medicine, vol. 69, pp. 172-177. 
[13] O'Hanlon, M. E. and Campbell, J. H. (October 1, 2007). Iraq Index. The Brookings Institution. Retrieved from: http:/www.brookings.edu/fp/saban/iraq/index.pdf

[14] Boafo, I. (2016). Ghanaian nurses' emigration intentions: the role of workplace violence. International Journal of Africa Nursing Sciences, vol. 5, pp. 29-35.

[15] Kapoor, M. C. (2017). Violence against the medical profession. Journal of Anaesthesiology Clinical Pharmacology, vol. 33, pp. 145-147.

[16] Tian, Y., Yue, Y., Wang, G., et al. (2020). Workplace violence against hospital healthcare workers in China: a national WeChat-based survey. BMC Public Health, vol. 20, article 582.

[17] di Martino, V. (2002). Workplace Violence in the Health Sector: Country Case Studies - Brazil, Bulgaria, Lebanon, Portugal, South Africa, Thailand and an additional Australian study. Retrieved from: https://www.who.int/violence_injury_prevention/ injury/en/WVsynthesisreport.pdf

[18] Mento, C., Silvestri, M., Bruno, A., et al. (2020). Workplace violence against healthcare professionals: a systematic review. Aggression and Violent Behavior, vol. 51, p. 101381.

[19] Sun, T., Gao, L., Li, F., et al. (2017). Workplace violence, psychological stress, sleep quality and subjective health in Chinese doctors: a large cross-sectional study. BMJ Open, vol. 7, no. 12, p. e017182.

[20] Gong, Y., Han, T., Yin, X., et al. (2014). Prevalence of depressive symptoms and work-related risk factors among nurses in public hospitals in southern China: a crosssectional study. Scientific Reports, vol. 4, p. 7109.

[21] Xu, T., Magnusson Hanson, L. L., Lange, T., et al. (2018). Workplace bullying and violence as risk factors for type 2 diabetes: a multicohort, study and meta-analysis. Diabetologia, vol. 61, no. 1, pp. 75-83.

[22] Xu, T., Magnusson Hanson, L. L., Lange, T., et al. (2019). Workplace bullying and workplace violence as risk factors for cardiovascular disease: a multi-cohort study. European Heart Journal, vol. 40, no. 14, pp. 1124-1134.

[23] Kitaneh, M. and Hamdan, M. (2012). Workplace violence against physicians and nurses in Palestinian public hospitals: a cross-sectional study. BMC Health Services Research, vol. 12, no. 1.

[24] ILO/ICN/WHO/PSI. (2002). Workplace Violence in the Health Sector - Country Case Studies Research Instrument - Survey Questionnaire. Geneva, Switzerland: ILO/ICN/WHO/PSI Joint Programme on Workplace Violence in the Health Sector. 
[25] Gerberich, S., Church, T., McGovern, P., et al. (2004). An epidemiological study of the magnitude and consequences of work related violence: the Minnesota Nurses' Study. Occupational and Environmental Medicine, vol. 61, no. 6, pp. 495-503.

[26] Abbas, M. A., Fiala, L. A., Abdel Rahman, A. G., et al. (2010). Epidemiology of workplace violence against nursing staff in Ismailia Governorate, Egypt. Journal of the Egyptian Public Health Association, vol. 85, no. 1-2, pp. 29-43.

[27] Algwaiz, W. M. and Alghanim, S. A. (2012). Violence exposure among health care professionals in Saudi public hospitals: a preliminary investigation. Saudi Medical Journal, vol. 33, pp. 76-82.

[28] Abodunrin, O. L., Adeoye, O. A., Adeomi, A. A., et al. (2014). Prevalence and forms of violence against health care professionals in a South-Western city, Nigeria. Sky Journal of Medicine and Medical Sciences, vol. 2, no. 8, pp. 067-072.

[29] Fernandes, C. M., Bouthillette, F., Raboud, J. M., et al. (1999). Violence in the emergency department: a survey of health care workers. CMAJ, vol. 161, no. 10, pp. 1245-1248.

[30] Alameddine, M., Kazzi, A., El-Jardali, F., et al. (2011). Occupational violence at Lebanese emergency departments: prevalence, characteristics and associated factors. Journal of Occupational Health, vol. 9, pp. 455-464.

[31] Deeb, M. (2003). Workplace Violence in the Health Sector - Lebanon Country Case Study. Geneva, Switzerland: ILO/ICN/WHO/PSI Joint Programme on Workplace Violence in the Health Sector.

[32] AbuAIRub, R. F., Khalifa, M. F., and Habbib, M. B. (2007). Workplace violence among Iraqi hospital nurses. Journal of Nursing Scholarship, vol. 39, no. 3, pp. 281-288.

[33] El-Gilany, A. H., El-Wehady, A., and Amr, M. (2010). Violence against primary health care workers in Al-Hassa, Saudi Arabia. Journal of Interpersonal Violence, vol. 25, no. 4 , pp. $716-734$.

[34] Gillespie, G. L., Gates, D. M., Miller, M., et al. (2010). Workplace violence in healthcare settings: risk factors and protective strategies. Rehabilitation Nursing, vol. 35, no. 5, pp. 177-184.

[35] Abdellah, R. and Salama, K. (2017). Prevalence and risk factors of workplace violence against health care workers in emergency department in Ismailia, Egypt. Pan African Medical Journal, vol. 26, p. 21.

[36] Imran, N., Jawaid, M., Haider, I. I., et al. (2010). Bullying of junior doctors in Pakistan: a cross-sectional survey. Singapore Medical Journal, vol. 51, no. 7, p. 592.

[37] Ayranci, U., Yenilmez, C., Balci, Y., et al. (2006). Identification of violence in Turkish health care settings. Journal of Interpersonal Violence, vol. 21, no. 2, pp. 276-296. 
[38] Landau, S. and Bendalak, Y. (2007). Personnel exposure to violence in hospital emergency wards: a routine activity approach. Aggressive Behavior, vol. 34, no. 1, pp. 88-103.

[39] Ahmed, F., Khizar Memon, M., and Memon, S. (2018). Violence against doctors, a serious concern for healthcare organizations to ponder about. Annals of Medicine and Surgery, vol. 25, pp. 3-5.

[40] Swain, C. G., and Greenwood, R. (2014). Patient aggression experienced by staff in a New Zealand public hospital setting. The New Zealand Medical Journal, vol. 127, no. 1394, pp. 10-18.

[41] Erkol, H., Gökdoğan, M. R., Erkol, Z., et al. (2007). Aggression and violence towards health care providers-a problem in Turkey? Journal of Forensic and Legal Medicine, vol. 14 , no. 7 , pp. $423-428$.

[42] Ryan, J. A. and Poster, E. C. (1989). The assaulted nurse: short-term and long-term responses. Archives of Psychiatric Nursing, vol. 3, no. 6, pp. 323-331.

[43] Adib, S. M., Al-Shatti, A. K., Kamal, S., et al. (2002). Violence against nurses in healthcare facilities in Kuwait. International Journal of Nursing Studies, vol. 39, no. 4, pp. 469-478. 